\title{
Editorial
}

\section{Livestock waste treatment systems of the future: A challenge to environmental quality, food safety, and sustainability. OECD Workshop}

This Special Issue of Bioresource Technology is dedicated to selected contributions presented at the international Workshop: "Livestock waste treatment systems of the future: A challenge to environmental quality, food safety, and sustainability,” held 2-4 April, 2008, in Florence, South Carolina (USA) and sponsored by the OECD (Organisation for Economic Cooperation and Development), Co-operative Research Programme: Biological Resource Management for Sustainable Agricultural Systems, under Theme (1) - the Natural Resources Challenges, and Theme (2) - Sustainability in Practice. The aim of the Workshop was to focus on the current state of scientific information on the treatment of animal waste, with the intent to apply this information strategically towards enhancing livestock systems for both the sustainable use and protection of natural resources and sustainable production.

Currently the potential impact of manure on the environment represents one of the world agriculture's major challenges. Once dominated by many small operations as part of traditional crop-livestock farms, livestock production has become highly concentrated in large operations. This development has separated animal production from crop production. Thus, the amount of manure produced often exceeds local demand for use as fertilizer. When properly managed, manure can be used as a nutrient source for crops and to improve soil properties through accretion of soil organic matter. On the other hand, improperly managed manure can pose a threat to soil, water and air quality, and human and animal health. Treatment technologies can play an important role in the management of livestock manure by providing a more flexible approach to land application and acreage limitations, and by solving specific problems such as odors, pathogens, water pollution, ammonia emissions, greenhouse gas emissions, and phosphorus and heavy metal contamination of soils. Treatment can be enhanced with the use of biological, chemical, and physical methodologies, especially in combination as part of holistic systems that: 1) are integrated with the needs of the land and other agri-food activities, and 2) maximize the value of manure through energy production, nutrient concentration and recycling, GHG reductions and environmental credits, and other beneficial by-products. The challenge for many countries is how to implement such technologies both on a wider scale and economically.

The Workshop took a synergistic, multidisciplinary approach to discuss sustainable treatment practices, emerging technologies, and holistic systems to solve related problems and to provide direction on animal waste treatment systems of the future. The outputs are reflected in the scientific papers presented in this Special Issue of Bioresource Technology.

The first set of papers deal with the hygienic aspects of manure treatment and food safety. Pathogen reduction aspects of treatment have often been a secondary consideration. Limiting 
exposure to pathogens is a major concern of public health officials throughout the world. Martens and Böhm present an overview on the ability of different treatment methods for liquid and solid manures to inactivate pathogens. Composting, anaerobic and aerobic biological manure treatments can provide economical, routine preventive hygienic measures. In case of disease outbrakes, more drastic physical or chemical treatments such as thermal drying, irradiation, or quicklime application are required to reliably disinfect/pasteurize manure and byproducts. Millner reports the state of current issues, technical knowledge, and remaining challenges to be addressed in evaluating the relationships among bioaerosols, dust and odorant on animal and workers at animal production facilities and nearby communities. Standardization and validation of bioaerosol collection and analytical techniques in animal agriculture settings both indoor and outdoor are critical to evaluation of health effects from modern animal production systems. Venglovsky et al. discuss the hygienic and ecological risks of pathogen and antibiotic residues in animal manures, as well as the survival of bacterial and parasitic pathogens in manure before and after land application. An emerging concern is the occurrence of antibiotic resistant bacteria. Cliver discusses the risks of manure-borne zoonoses to public health via the food supply and policy-based strategies for mitigating threats to food safety. Decisions on preventive mandatory hygienic measures should be based on quantitative risks assessments comparing the impacts of alternative public health risk scenarios. Topp et al. present the beneficial impacts of livestock treatment systems for reducing environmental exposure to hazardous enteric pathogens. Quantitative microbial risk assessment approaches are being used to estimate the impact of manure treatment on risk to humans exposed to manured land. Manure collection and storage systems represent the first critical secondary habitat in which enteric bacteria must survive prior to release into the broader environment and cause of human illness. Innovative waste treatment systems are clearly a critical component of agricultural multi-barrier water protection strategies. Burton discusses the need to reconcile the new demands for food protection with the environmental goals in the management of livestock wastes. The sensible development of spreading plans in which high and low risk crops are identified can enable appropriate and effective treatment for each situation and minimize overall cost. For the high risk, "ready-to-eat" crops or manure exportation situations, biological treatment such as composting or anaerobic digestion with the implicit heating process is the best option. Process design to produce heat should be also considered.

A second group of contributions describe advanced treatment technologies for liquid manure. The examples show a shift from municipal treatment methods in the near past to a new body of knowledge with methods adapted to the specific characteristics of these wastes and a different purpose for treatment. For instance, solid-liquid separation of the raw manure increases the capacity of decision making and opportunities for treatment. Vanotti et al. present a case study in North Carolina of a system where mechanical separation is enhanced by using flocculant agents. The separation up-front allows recovery of the organic compounds, which can be used for the manufacture of compost materials and other value-added products or energy production. 
It also facilitates treatment of the liquid through biological nitrogen removal and phosphorus recovery/disinfection to meet specific environmental standards. Garcia et al. indicate that natural occurring flocculants such as chitosan can be as effective as synthetic polymers for the separation of solids and nutrients from concentrated dairy manure effluents. Natural compounds with flocculation capacity may have an important role in waste management because of increased cost of energy and renewed interest on organic farming systems. Bortone presents case studies in Italy that show the importance of solid-liquid separation in piggery wastewater for a successful integration of anaerobic and aerobic biological processes. This integration between anaerobic digestion and biological $\mathrm{N}$ removal provides a balance between the need to remove nutrient surpluses in nitrate vulnerable zones and goals of production of renewable energy from manure. Bernet and Beline discuss biological treatments available for livestock effluents as well as nutrient recovery options and future challenges. Global greenhouse gas emissions can be significantly reduced through aerobic processes or closed anaerobic digestion, but good management is critical. Biogas productivity of anaerobic digestion could be increased by pretreatment or co-digestion with other organic wastes and energy crops. For aerobic treatment, higher efficiencies could be achieved with partial nitrification/denitrification and anammox processes. Furukawa et al. present a novel technology for treatment of ammonia in biogas plant digested manure that combines the anammox process with new material sciences. By entrapping the autotrophic bacteria in polymer gel carriers, the process is not inhibited with high organic matter in these effluents. As a consequence, the removal rate is increased to a new level in biological treatment.

A third set of papers is concerned with the treatment technologies focusing on the utilization aspects of manure. Bernal et al. and Moral et al. contribute with two connected papers, presenting on advances in composting of animal manure and criteria for compost quality. Composting of animal manure should be seen as a technology that adds value, producing a high quality product focused on specific agricultural markets such as soilless media for nursery crops, orchard mulching, and organic farming. The quality criteria are established in terms of nutrient content, humified and stabilized organic matter, the maturity degree, hygienisation, and the presence of toxic compounds. Co-composting and additive strategies as well as new analytical techniques should be considered for the improvement of process control and compost quality. Szogi and Vanotti discuss the prospects of phosphorus recovery from poultry litter using emerging alternative technologies that produce phosphorus concentrated byproducts which can facilitate phosphorus transport and its effective reutilization. Options include densification, biological, thermochemical, and chemical quick wash processes that produce materials with varied phosphorus content and environmental benefits such as water quality credits. Ro et al. present a method of thermochemical conversion for swine manure solids using slow pyrolysis that requires relatively low technical resources, making the technology suitable for on-farm use. The process produces charcoal or bio-char, a carbon-stabilized material with potential use as soil amendment to enhance soil quality and long-term carbon sequestration. Zhu et al. examine the 
technical feasibility of fermenting liquid swine manure in combination with sugars to produce biohydrogen, a clean energy source that has potential to replace the fossil fuel in the future. The efficiency and health of the hydrogen fermentation could be greatly increased by controlling process $\mathrm{pH}$ and eliminating methane content in the reactor. Holm-Nielsen et al. discuss the future of anaerobic digestion of manure. The technology offers several environmental benefits and production of a clean, renewable fuel - the biogas - for multiple utilizations, with potential to fulfill many national policy objectives (agricultural, environmental, and energy). Biogas penetration on the energy market will probably accelerate as a consequence of the growing share of renewables in the world's energy supply, how fast it depends on creating favorable national political and economical frame conditions.

The last group of contributions is dedicated to the development of holistic treatment systems and the environmental and society benefits from its implementation. Kunz et al. discuss advanced swine manure treatment in Brazil to solve several potential environmental problems linked to a new reality of rapid expansion and industrial production. The new systems integrate solid-liquids separation, biodigestors and aerobic processes with the aim of increasing farm revenue through its by-products (carbon credits, fertilizer, and biogas) while significantly reducing environmental impact. Bolan et al. discuss integrated methods developed for dairy farm effluents in New Zealand to improve water quality. Successful approaches include advanced pond systems using anaerobic digestion, aerobic algae, settling and polishing stages, the use of absorbing materials to capture and recycle nutrients, and land application strategies involving nutrient budgeting and water models to enhance forage production and protect against off-site environmental pollution. Harrington and McInnes present the Integrated Constructed Wetland (ICW) concept for social, economic, and environmental coherence in the management of livestock wastewater, supported by a case study on a catchment in Ireland. The ICW concept integrates three linked objectives: water quantity and quality management, landscape-fit to improve site aesthetic values, and enhanced biodiversity. Melse and Timmerman discuss early experiences in the Netherlands to apply manure treatment techniques. Causes of failure include centralized facilities with treatment similar to municipal plants and high processing costs, onfarm facilities too complex to operate, limited market for products as fertilizer replacement, and changes in government subsidies. Air treatment technologies being implemented are acid ammonia scrubbers, bio-scrubbers with nitrification/denitrification, and multi-pollutant scrubbers for additional odor and dust control. Williams presents research and policy initiatives in the U.S. to develop and incorporate environmentally superior technologies that address impacts of swine manure to surface and ground water, emission of ammonia and odor, pathogens, and heavy metal contamination. The optimal method of achieving net cost reductions and even positive revenue flows from these superior technologies is to install targeted technologies on a sufficient number of farms to facilitate engineering improvements and value-added product market development. Flotats et al. examine strategies for manure treatment technology based on a case study in NE Spain. Decision on individual vs. centralized treatment must result from nutrient management 
planning, taking into account the density and the intensity of farming in the region, local conditions, and cultivable soils as end-users. In all cases, successful implementation requires the involvement of farmers, technology suppliers, and related authorities. Martinez et al. present an outlook for livestock waste treatment systems taking into account global trends in livestock production and intensive farming practices along with their environmental impacts on water, air and soil pollution. There is clearly no best treatment solution, but rather a range of options, technological or natural, which needs to be integrated, adapted, and implemented according to local situation and context (social, economical, regulatory). New waste management methods should protect the environment and allow management to switch back to a recycling view of manure handling. Technologies allowing nutrient recycling from wastes, especially phosphorus, are needed, as well as any technique allowing an economical and environmental benefit like better agronomic use or biogas production from manure.

One of the main outputs of the Workshop was the importance of collaborative links, cooperation and integration of research activities and practices, and on setting clear goals to solve problems. Animal production and management of its wastes are strategic for the economy, food security, public health, and environmental protection of each country. Many commonalities on holistic treatment solutions to manure management were recognized by the participants; however, in each country it is important to identify the regional and/or national animal waste problems, set goals, and develop customized solutions to achieve these goals. In addition to typical goals of improved air, soil and water quality, and animal and public health, the delegates concluded that future treatment systems should also address nutrient recovery, energy, and water conservation. This OECD-sponsored workshop will provide a stronger recognition of the global importance of livestock waste treatment both for society and farmers.

We acknowledge with gratitude the sponsor and the co-sponsors of the Workshop: The Co-operative Research Programme of the OECD, the United States Department of Agriculture (USDA) - Agricultural Research Service (ARS) and Foreign Agriculture Service (FAS), and FAO Research Network on Recycling of Agricultural and Industrial Residues in Agriculture Network (RAMIRAN). We thank also OECD-CRP Theme 1 and 2 Coordinators, Drs. E. John Sadler and Gary Fitt, for their contributions to the success of the Workshop.

Matias Vanotti

Ariel Szogi

United States Department of Agriculture, Agricultural Research Service, Coastal Plains Research Center, 2611 W. Lucas St., Florence, South Carolina 29501, USA; Tel.: +1 843669 5203; Fax: +1 843669 6970; E-mail addresses: matias.vanotti@ars.usda.gov (M. Vanotti), ariel.szogi@ars.usda.gov (A. Szogi) 
$\mathrm{M}^{\mathrm{a}}$ Pilar Bernal

Department of Soil and Water Conservation and Organic Waste Management, Centro de Edafología y Biología Aplicada del Segura, CSIC, P.O. Box 164, 30100 Murcia, Spain; Tel.:

+34 968 396200; fax: +34 968 396213; E-mail address: pbernal@cebas.csic.es

José Martinez

Cemagref, Environmental and Biological Treatment of Wastes Research Unit, 17 Avenue de Cucillé, CS 64427, 35044 Rennes, Cedex, France; Tel.: +33 2234821 30; fax: +33 2234821

15; E-mail address: jose.martinez@cemagref.fr

\section{Special Issue Information}

Accreditation:

The Workshop "Livestock waste treatment systems of the future: A challenge to environmental quality, food safety, and sustainability” was sponsored by the OECD Co-operative Research Programme: Biological Resource Management for Sustainable Agricultural Systems, whose financial support made it possible for most of the invited speakers to participate in the Workshop.

OECD Disclaimer:

The opinions expressed and arguments employed in this publication are the sole responsibility of the authors and do not reflect those of the OECD or of the governments of its Member countries. 